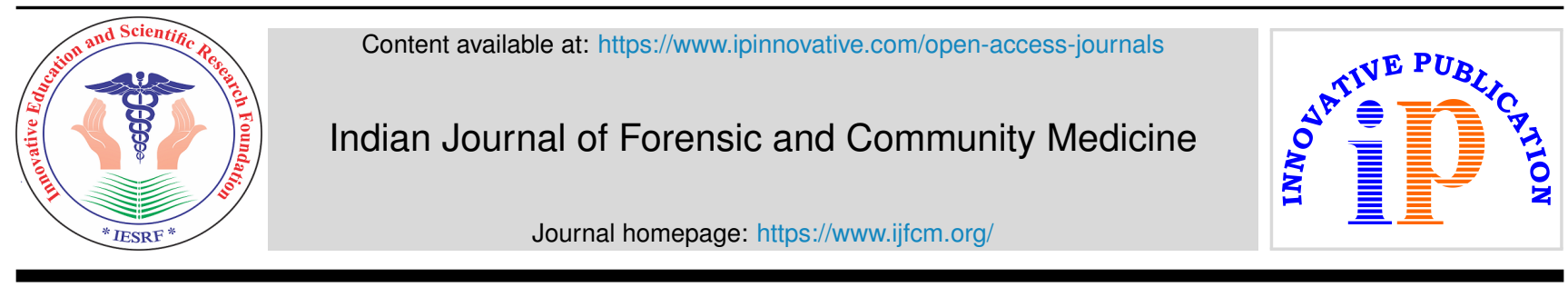

\title{
Editorial
}

\section{Scenario of medical education after Covid in India}

\author{
Bhola Nath ${ }^{\circledast 1}$, Ranjeeta Kumari ${ }^{\circledR 2}$,*, Madhukar Mittal ${ }^{3}$, Hem Chandra ${ }^{4}$ \\ ${ }^{1}$ Dept. of Community and Family Medicine, All India Institute of Medical Sciences, Bathinda, Punjab, India \\ ${ }^{2}$ Dept. of Community and Family Medicine, All India Institute of Medical Sciences, Rishikesh, Uttarakhand, India \\ ${ }^{3}$ Dept. of Endocrinology and Metabolism, All India Institute of Medical Sciences(AIIMS), Jodhpur, Rajasthan, India \\ ${ }^{4}$ HNB Medical University, Dehradun, Uttarakhand, India
}

\section{A R T I C L E I N F O}

Article history:

Received 07-09-2021

Accepted 14-09-2021

Available online 18-09-2021

\begin{abstract}
This is an Open Access (OA) journal, and articles are distributed under the terms of the Creative Commons Attribution-NonCommercial-ShareAlike 4.0 License, which allows others to remix, tweak, and build upon the work non-commercially, as long as appropriate credit is given and the new creations are licensed under the identical terms.

For reprints contact: reprint@ipinnovative.com
\end{abstract}

\section{Introduction}

The recent crisis of Covid 19 pandemic has created an unprecedented challenge to health systems across the globe. In current times, social distancing is the most effective preventive strategy since the emergence of SARS CoV2 disease pending development of an effective treatment, vaccine or both. ${ }^{1}$ But along with, it has posed questions for the medical education system. Due to social distancing norms and fear of spread, it has been inevitable to close medical colleges and higher institutions for teaching purposes. In many countries around the world like China and Canada, the impact of previous SARS epidemic led to delayed exams, stopping of clerkships for as long as 6 weeks. $^{2,3}$ But the course and timeline of impact of the disease in the Indian population still in evolution, it may severely hamper the accessibility of education to the medical students resulting in loss of academic learning, semesters, and delay in academic calendars etc. Along these lines many medical schools and universities across the globe are gradually switching to online platforms to maintain the continuity of medical education. ${ }^{4}$

\footnotetext{
* Corresponding author.

E-mail address: rkaiims2012@gmail.com (R. Kumari).
}

\section{Present Scenario of Medical Education in India}

The Indian medical system has witnessed tremendous change in recent years with a revamp in the curriculum. There have been new additions of many relevant topics to make it a competency based undergraduate curriculum. But, Covid has brought the classroom teaching to a standstill with most of the medical colleges having closed classroom teaching. One of the most immediate changes introduced has been the broad cancelling of in-person medical classes, with most being replaced by recorded lectures or videos using platform like Zoom, Microsoft team etc. Though it would be relatively simpler for theory classes it would be a daunting task for practical assignments which require hands-on training. In India, we have been following the traditional teacher-centric pattern which does not deploy advanced technologies in medicine as much as developed countries. So the transition to the online system would be a difficult and more challenging task. Though some of private institutions may find it easier to adjust to the revamped system, government institutions will find it hard with limited resources.

\section{Need for Change}

It would need revamping of the existing guidelines for integration of online teaching platforms into the existing 
teaching systems. Also the upcoming medical colleges should make it mandatory beforehand to include newer methodologies like e-learning and tools, including remote learning, virtual classrooms, etc. Many institutes like NIMHANS, AIIMS New Delhi, SGPGI Lucknow are using virtual classrooms and telemedicine services for reaching out to other medical colleges/health professionals to maintain a network of online teaching platform in the country. During this pandemic, we are seeing various institutions of national importance regularly sharing and updating the guidelines regarding Covid 19. The websites and portals of the Government of India (All India Institute of Medical Sciences AIIMS, MoHFW, ICMR) are providing updated resources, guidelines, and dashboards for education and awareness related to COVID 19. This needs to be practiced in future where there is a more knowledge sharing among the medical colleges all across the country.

Another way in which COVID-19 has affected medical education is the cancelling of medical conferences. These conferences, and the associated presentations that medical students give, are essential to building up their capacities and interactions with the experts in the field. In the near future these can be replaced by webinars and sharing of live lectures on relevant topics for further learning. The younger generation students in medical colleges are perhaps best equipped to integrate technology and webinars into health care delivery and sharing medical knowledge in innovative, online settings. ${ }^{5}$ Online learning resources if properly used have been shown to have positive effects as long as the student participates actively. ${ }^{6}$

Indian medical education still does not focus more on Evidence-based and research-based learning. Pandemics like Covid 19 have taught us that we need to be prepared with practical solutions to these challenges. This method of medical education gives a great difference in learning outcomes which is competency-based, such methods will help the students have a holistic understanding of the subject and have a more rational practical approach. Apart from teaching, we need to emphasize on research to make the teaching more goal oriented. They need to be encouraged for academic writing with the help of senior faculty who would be more resourceful and guide them in this aspect. Early clinical exposure as introduced recently in our curriculum will be helpful in acquiring a research and inquisitive mindset. Case based learning can be given importance in this changing scenario. Relatively newer techniques of medical education like small group teaching and problem based learning can be integrated to the curriculum with modifications in the Indian context considering their success in the foreign university medical schools. Implementing technology into medical education in a unique way will allow students to develop collaborative skills and improve adaptability.

\section{Conclusions}

Indian medical education system is evolving day by day and striving to reach international standards. The Covid 19 pandemic has given an opportunity to transform the existing medical education scenario. It gives a chance to adapt and imbibe newer modes of learning like tele-health, online learning with a flexible approach. ${ }^{7}$ Teachers all over the medical field in India should contribute in the advancement of medical education with the requisite changes in the curriculum and transformations across various disciplines in medicine. Regardless of the difficulties that the students and teachers would face in these disturbing times of the pandemic, it would provide them a silver lining to change the face of medical education in the country for the better.

\section{Conflict of Interest}

None.

\section{References}

1. Rio C, Malani PN. 2019 Novel Coronavirus-Important Information for Clinicians. JAMA. 2019;323(11):1039-40. ॠ01:10.1001/jama.2020.1490.

2. Patil NG, Yan YC. SARS and its effect on medical education in Hong Kong. Med Educ. 2003;37:1127-28.

3. Clark J. Fear of SARS thwarts medical education in Toronto. BMJ. 2003;326:784.

4. Association of Indian Universities. AIU. Available from: https:// aiubloggroup.wordpress.com.

5. Ferrel MN, Ryan JJ. The Impact of COVID-19 on Medical Education. Cureus. 2020;31(3):e7492. dol:10.7/59/cureus.7492

6. Bientzle M, Hircin E, Kimmerle J, Knipfer C, Smeets R, Gaudin R, et al. Association of Online Learning Behavior and Learning Outcomes for Medical Students: Large- Scale Usage Data Analysis. JMIR Med Educ. 2019;5(2):e13529.

7. Rose S. Medical Student Education in the Time of COVID-19. JAMA 2020;323(21):2131-2. do1:10.1001/jama.2020.5227.

\section{Author biography}

Bhola Nath, Additional Professor (1) https://orcid.org/0000-00-03-43150829

Ranjeeta Kumari, Additional Professor (1) https://orcid.org/0000-0002$5242-2198$

Madhukar Mittal, Additional Professor

Hem Chandra, Vice Chancellor

Cite this article: Nath B, Kumari R, Mittal M, Chandra H. Scenario of medical education after Covid in India. Indian J Forensic Community Med 2021;8(3):141-142. 